Supplement of Atmos. Chem. Phys., 21, 5739-5753, 2021

https://doi.org/10.5194/acp-21-5739-2021-supplement

(C) Author(s) 2021. CC BY 4.0 License.

(c) (i)

Supplement of

\title{
The impact threshold of the aerosol radiative forcing on the boundary layer structure in the pollution region
}

Dandan Zhao et al.

Correspondence to: Jinyuan Xin (xjy@ mail.iap.ac.cn)

The copyright of individual parts of the supplement might differ from the article licence. 


\section{This file includes:}

\section{S1. Introduction to other datasets:}

The virtual potential temperature $\left(\theta_{\mathrm{v}}\right)$ and pseudo-equivalent potential temperature $\left(\theta_{\mathrm{se}}\right)$ are calculated with Equations (1) and (2), respectively:

$$
\begin{aligned}
& \theta_{\mathrm{v}}=T(1+0.608 q)\left(\frac{1000}{P}\right)^{0.286} \\
& \theta_{\mathrm{se}}=T\left(\frac{1000}{P}\right)^{0.286} \exp \left(\frac{r_{s} L_{v}}{c_{p d} T}\right)
\end{aligned}
$$

where $T$ is the air temperature, $q$ is the specific humidity, $P$ is the air pressure, $r_{s}$ is the saturation mixing ratio, $L_{v}$ is the latent heat of vaporization at $2.5 \times 10^{6} \mathrm{~J} \mathrm{~kg}^{-1}$, and $c_{p d}$ is the specific heat of air of $1005 \mathrm{~J} \mathrm{~kg}^{-1} \mathrm{~K}^{-1}$. All the relevant parameters can be calculated from the temperature and humidity profile data obtained with the MWR, and the values of $\theta_{\mathrm{v}}$ and $\theta_{\mathrm{se}}$ at different altitudes can be then further obtained.

The hourly TKE is calculated by instantaneous three wind components sampled by Doppler wind lidar every five seconds, shown as Equations (3)-(6). The calculated TKE profile has a spatial resolution ranging from $1-20 \mathrm{~m}$ up to $0.3 \mathrm{~km}$ and a spatial resolution of $25 \mathrm{~m}$ from 0.3 to $3 \mathrm{~km}$, at a temporal resolution of one hour.

$$
\mathrm{TKE}=\frac{\sqrt{\delta_{u}^{2}+\delta_{v}^{2}+\delta_{w}^{2}}}{2}
$$

The one-hour vertical velocity standard deviation $\left(\delta_{w}^{2}\right)$ and one-hour horizontal wind standard deviation $\left(\delta_{u}^{2}, \delta_{v}^{2}\right)$ are calculated with Equations (4)-(6), respectively

$$
\delta_{w}^{2}=\frac{1}{N-1} \sum_{i=1}^{N}\left(w_{i}-\bar{w}\right)^{2}
$$




$$
\begin{gathered}
\delta_{u}^{2}=\frac{1}{N-1} \sum_{i=1}^{N}\left(u_{i}-\bar{u}\right)^{2} \\
\delta_{v}^{2}=\frac{1}{N-1} \sum_{i=1}^{N}\left(v_{i}-\bar{v}\right)^{2}
\end{gathered}
$$

where $N$ is the number of records per hour, $w_{i}$ is the vertical wind velocity $\left(\mathrm{m} \mathrm{s}^{-1}\right)$ at $i_{\text {th }}$ level, $u_{i}\left(v_{i}\right)$ is the horizontal wind speed $\left(\mathrm{m} \mathrm{s}^{-1}\right)$ at $i_{\text {th }}$ level, $\bar{w}$ is the mean vertical wind speed $\left(\mathrm{m} \mathrm{s}^{-1}\right)$, and $\bar{u}(\bar{v})$ is the mean horizontal wind speed $\left(\mathrm{m} \mathrm{s}^{-1}\right)$ (Banta et al., 2006; Wang et al., 2019). 


\section{Figures S1-S4:}
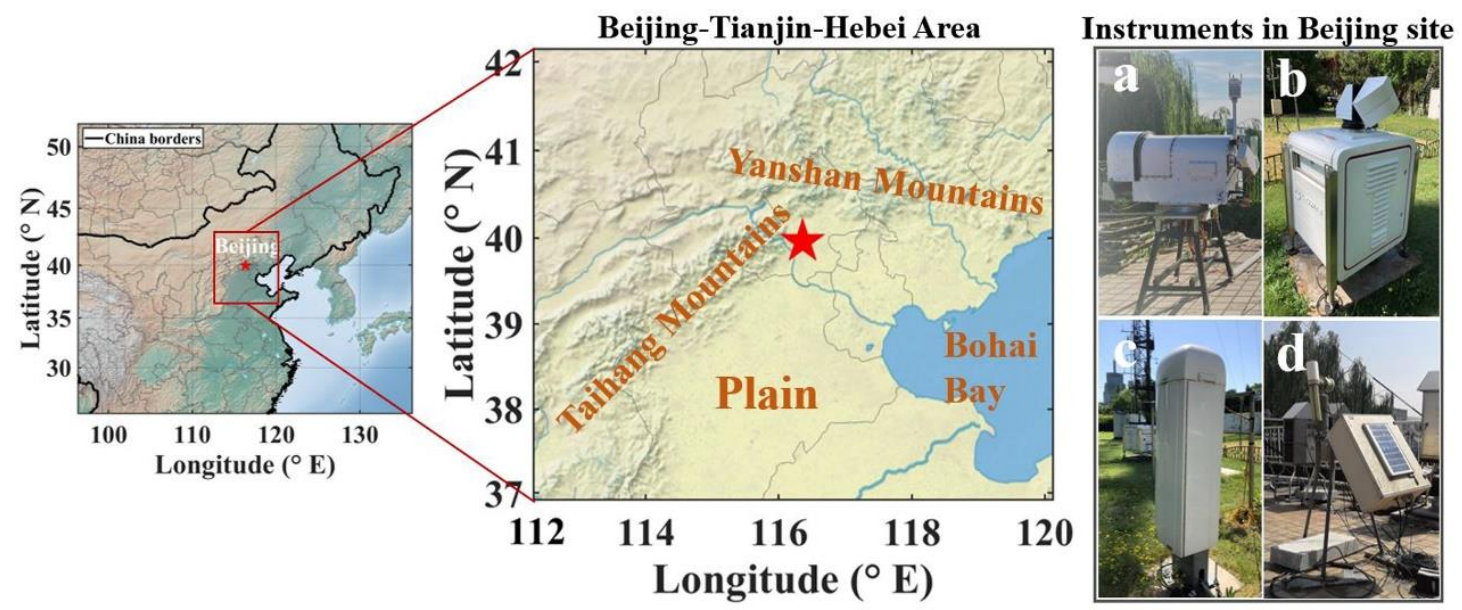

Figure S1. Left panel is the topographic distribution of most China with Beijing marked by a red star, the middle graph shows the Beijing-Tianjin-Hebei region with the Yanshan Mountains to the north, the Taihang Mountains to the west, and Bohai Bay to the east, and the right panel is the observation instruments with (a) microwave radiometer, (b) wind profile lidar, (c) ceilometer, and (d) sun-photometer used in this study. 

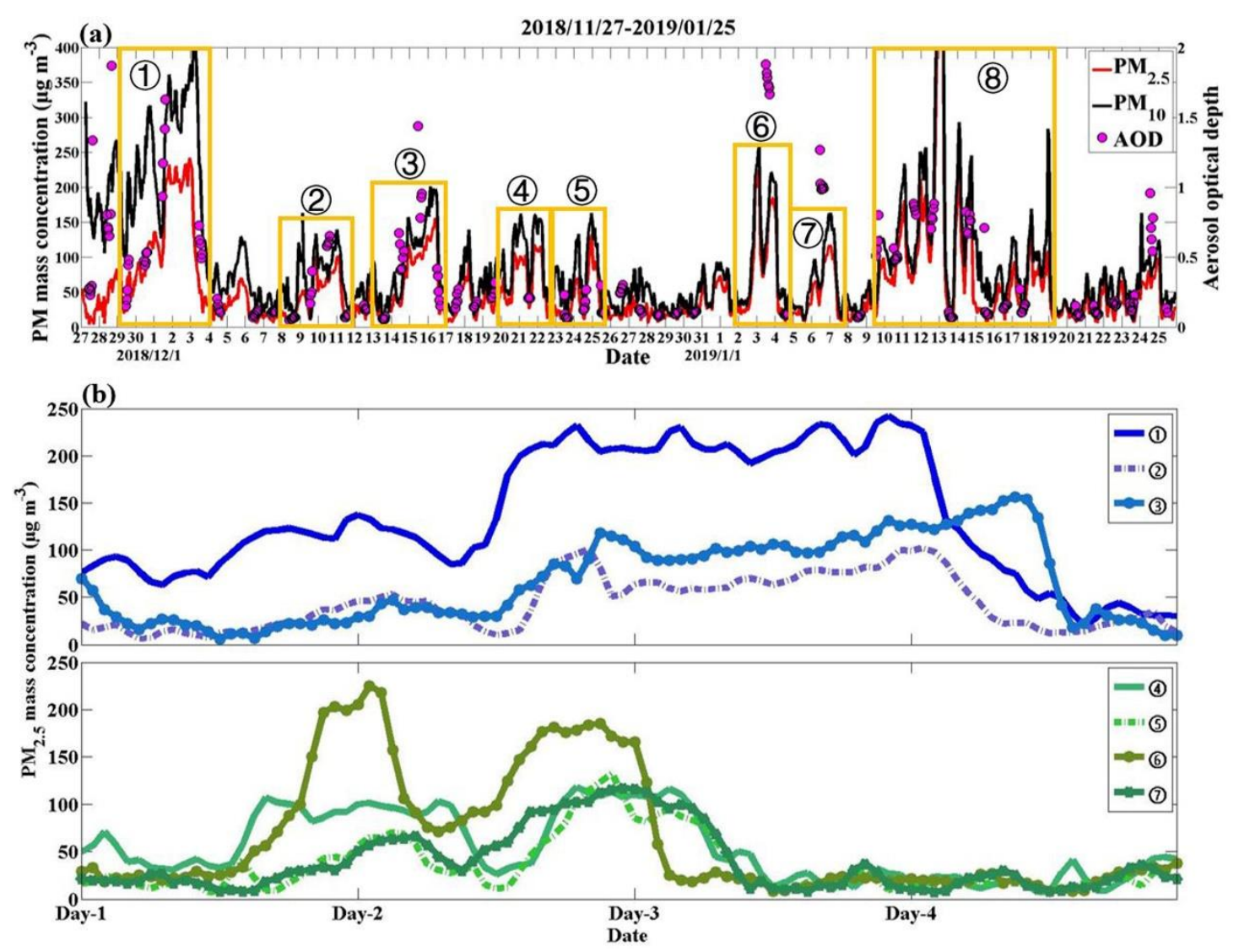

Figure S2. (a) Temporal evolutions of the PM mass concentration $\left(\mathrm{PM}_{2.5}\right.$ : solid red lines; $\mathrm{PM}_{10}$ : solid black lines) and aerosol optical depth (AOD; pink circles) from 27 November 2018 to 25 January 2019 in Beijing, with circled boxes represent typical haze pollution episodes named by (1)-(8). (b) Temporal evolutions of the $\mathrm{PM}_{2.5}$ mass concentration during typical haze pollution episodes (1)-(7) in Beijing in winter. 

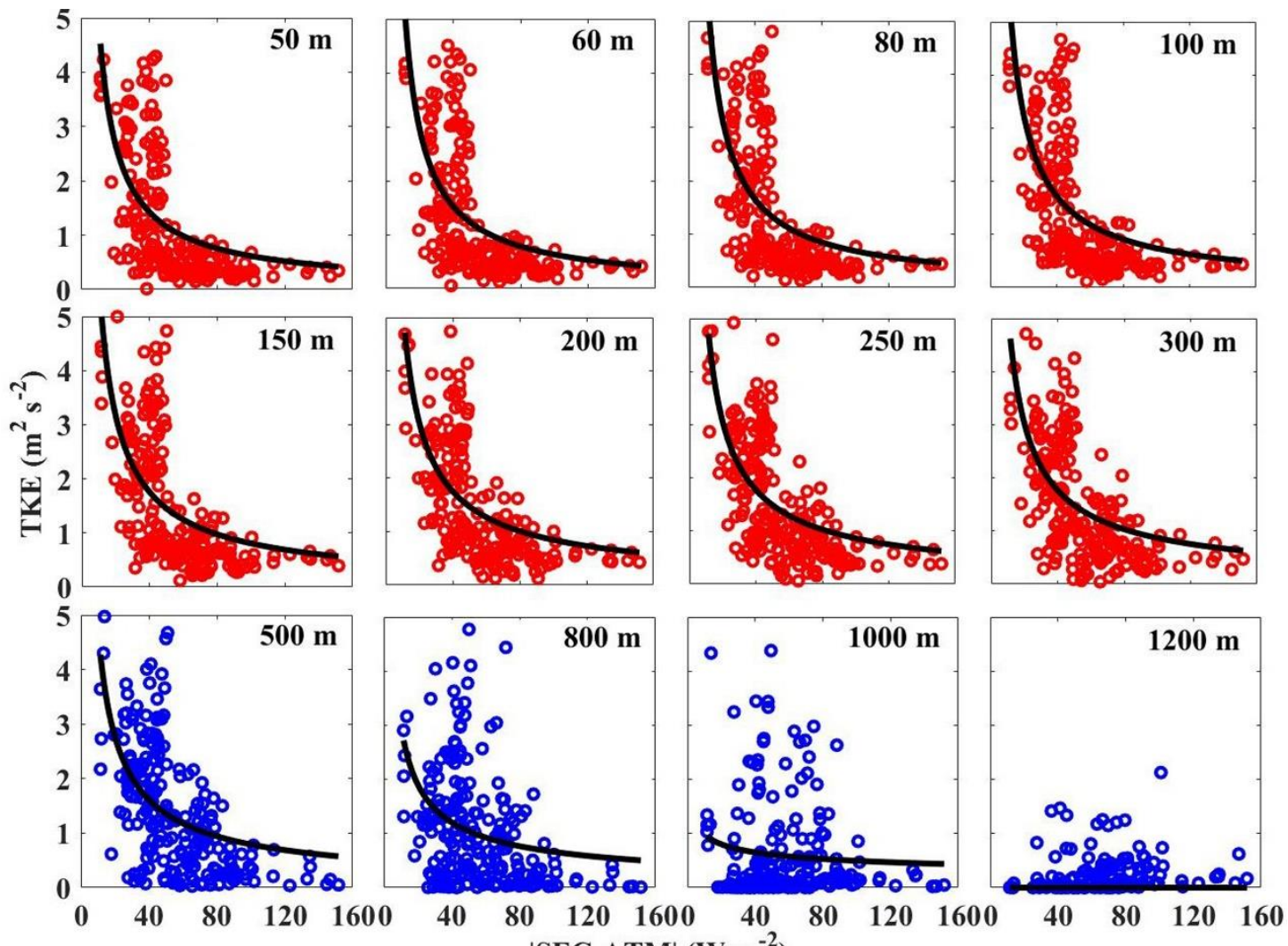

Figure S3. Scatter plots of the absolute difference of aerosol radiative forcing at the surface and interior of the atmospheric column (|SFC-ATM|; $x$ ) versus turbulence kinetic energy (TKE; $y$ ) at different altitudes. The calculated hourly data used above were collected over a two-month period in Beijing from 27 November 2018 to 25 January 2019. 

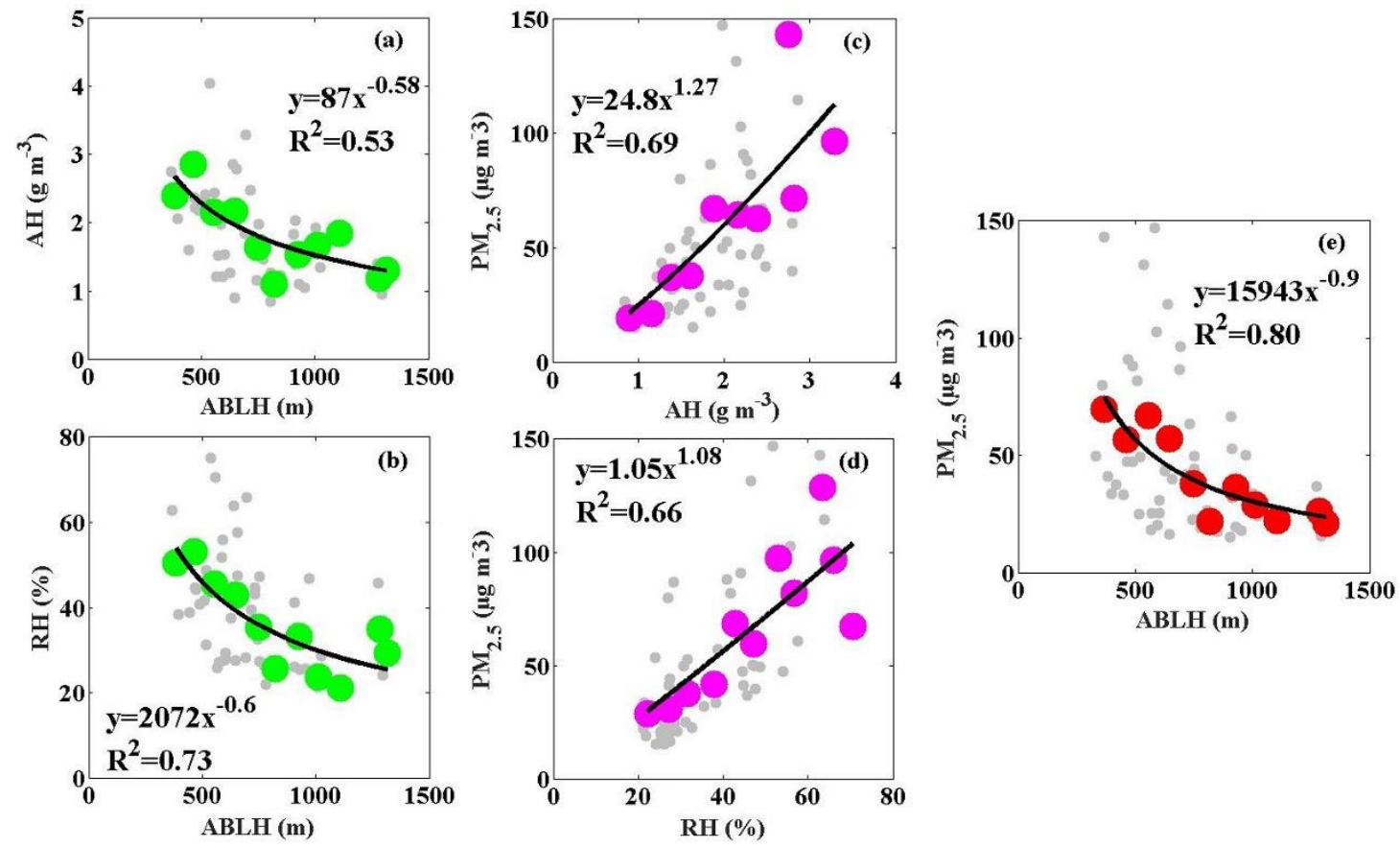

Figure S4. Scatter plots between the atmospheric boundary layer height (ABLH), water vapor density (AH), relative humidity (RH), and $\mathrm{PM}_{2.5}$ concentration. (a) ABLH vs. AH; (b).... The calculated daily data used above were over a two-month period in Beijing from 27 November 2018 to 25 January 2019 (gray dots: daily data; other dots: mean data). 


\section{Table S1-S2:}

Table S1. Equations $\left(y=a x^{b}\right)$ and correlation coefficient $\left(\mathrm{R}^{2}\right)$ of the fitted curves in Figure S5 and Figures 4-5.

\begin{tabular}{|c|c|c|c|c|c|c|c|c|c|}
\hline \multirow[b]{2}{*}{$\mathrm{H}(\mathrm{m})$} & \multicolumn{3}{|c|}{$\mid$ SFC-ATM $\mid$ vs. TKE } & \multicolumn{3}{|c|}{$\begin{array}{l}\text { mean } \mid \text { SFC-ATM } \mid \text { vs. } \\
\text { mean TKE }\end{array}$} & \multicolumn{3}{|c|}{ TKE vs. ABLH } \\
\hline & $\mathrm{a}$ & $\mathrm{b}$ & $\mathrm{R}^{2}$ & $\mathrm{a}$ & $\mathrm{b}$ & $\mathrm{R}^{2}$ & $\mathrm{a}$ & $\mathrm{b}$ & $\mathrm{R}^{2}$ \\
\hline 50 & 43.13 & -0.92 & 0.40 & 46.90 & -0.97 & 0.91 & 844.19 & 0.18 & 0.13 \\
\hline 60 & 53.77 & -0.96 & 0.40 & 60.47 & -1.02 & 0.92 & 827.38 & 0.19 & 0.14 \\
\hline 80 & 57.23 & -0.96 & 0.41 & 66.45 & -1.02 & 0.93 & 816.67 & 0.18 & 0.13 \\
\hline 100 & 51.93 & -0.92 & 0.40 & 61.69 & -0.99 & 0.93 & 805.28 & 0.19 & 0.14 \\
\hline 150 & 40.46 & -0.85 & 0.41 & 46.10 & -0.91 & 0.92 & 792.45 & 0.22 & 0.15 \\
\hline 200 & 33.10 & -0.79 & 0.39 & 35.78 & -0.84 & 0.91 & 785.18 & 0.24 & 0.15 \\
\hline 250 & 32.09 & -0.78 & 0.41 & 35.64 & -0.84 & 0.92 & 782.58 & 0.23 & 0.14 \\
\hline 300 & 30.64 & -0.78 & 0.40 & 33.68 & -0.82 & 0.92 & 789.77 & 0.21 & 0.13 \\
\hline 500 & 29.08 & -0.78 & 0.34 & 41.96 & -0.92 & 0.88 & 828.54 & 0.19 & 0.17 \\
\hline 800 & 13.45 & -0.65 & 0.14 & 26.54 & -0.89 & 0.82 & 895.95 & 0.15 & 0.18 \\
\hline 1000 & 1.96 & -0.30 & 0.01 & 6.77 & -0.67 & 0.53 & 944.42 & 0.05 & 0.05 \\
\hline 1200 & 4.03 & -12.40 & 0.02 & 0.08 & -0.25 & 0.05 & 801.90 & -0.03 & 0.03 \\
\hline In & 25.46 & -0.76 & 0.40 & 29.72 & -0.83 & 0.91 & $* * *$ & $* * *$ & $* * *$ \\
\hline Above & 0.70 & -0.15 & 0.01 & 1.01 & -0.28 & 0.29 & $* * *$ & $* * *$ & $* * *$ \\
\hline
\end{tabular}


Table S2. Input parameters of SBDART model.

\begin{tabular}{ll}
\hline MODULES & OPTIONS \\
\hline $\begin{array}{l}\text { Wavelength limits, filter } \\
\text { function specification }\end{array}$ & 1. WLINF: Lower wavelength limit \\
2. WLSUP: Upper wavelength limit \\
3. WLINC: Spectral resolution of the SBDART run \\
4. IDAY: Day number of the year \\
5olar geometry \\
$\begin{array}{l}\text { 6. TIME: UTC time in decimal hours } \\
\text { 7. ALON: East longitude of point on earth's surface }\end{array}$ \\
8. SZA: Solar zenith angle \\
9. ISALB: Surface albedo feature \\
properties
\end{tabular}

\section{References:}

Banta, R. M., Pichugina, Y. L., and Brewer, W. A.: Turbulent velocity-variance profiles in the stable boundary layer generated by a nocturnal low-level jet, J. Atmos. Sci., 63, 2700-2719, https://doi.org/10.1175/jas3776.1, 2006.

Wang, L., Liu, J., Gao, Z., Li, Y., Huang, M., Fan, S., Zhang, X., Yang, Y., Miao, S., 
Zou, H., Sun, Y., Chen, Y., and Yang, T.: Vertical observations of the atmospheric boundary layer structure over Beijing urban area during air pollution episodes, Atmos. Chem. Phys., 19, 6949-6967, https://doi.org/10.5194/acp-19-6949-2019, 2019. 